\title{
The Interaction of Oligosaccharide-Branched Cyclodextrins with Immobilized Concanavalin A
}

\author{
Hideo Imata, Kohji Kubota, Kenjiro Hattori, ${ }^{\dagger}$ \\ Masaaki Aoyagi, ${ }^{*}$ and Chiaki JinDOH* \\ Faculty of Engineering, Tokyo Institute of Polytechnics, \\ 1583 Iiyama, Atsugi, Kanagawa 243-02, Japan \\ * Scientific Instrument Sales Laboratory, Nissei Sangyo Co., Ltd., \\ 20-1 Morinosato Aoyama, Atsugi, Kanagawa 243-01, Japan
}

(Received November 11, 1996)

\begin{abstract}
New oligosaccharide-branched $\beta$-cyclodextrins $(\mathbf{1 0}-12)$ having various oligosaccharides in the primary (C6) hydroxyl group of $\beta$-cyclodextrin (CD) were synthesized. Oligosaccharides were converted to lactones at the reducing end, which was connected with 6-monoamino- $\beta$-CD forming an amide bond. They were examined for the interaction with the immobilized concanavalin A (Con A) and compared to available 6-O-glucosyl and maltosyl CDs (1-9). For the analysis of the interaction between Con A immobilized on an aminosilane-hydrogel surface and various oligosaccharides, a biosensor of the FISONS IAsys apparatus based on a resonant mirror detector (RMD) was used. As a result, it interacted with immobilized Con $\mathrm{A}$ and both maltosyl- $\beta$-CD (6) and maltosyl- $\gamma-\mathrm{CD}(9)$, and glucosyl-glucono-amide- $\beta$ - $\mathrm{CD}(\mathbf{1 0})$ with association constants, $K_{\mathrm{a}}$, of 134,833 , and $8570 \mathrm{M}^{-1}$, respectively. Con A showed the distinct sugar chain recognition to glucosyl-glucono-amide- $\beta$-CD (10). The other oligosaccharide-branched CDs showed rather complicated and obscure interaction.

KEY WORDS Branched Cyclodextrin / Concanavalin A / Lectin / Molecular Recognition / Sugar Chain Recognition / Oligosaccharide Interaction / Optical Biosensor /
\end{abstract}

Cyclodextrin (CD) can be used in various drugs as auxiliary additives such as carriers, diluents and solubilizers of tablet ingredients. ${ }^{1,2}$ On the other hand, biological recognition and adhesion processes often involve the formation of saccharide-protein complexes. Elucidation of saccharide-binding specificity for lectin proteins has become important when connected with the biological recognition and adhesion processes. ${ }^{3}$ In order to construct the targeting drug delivery system, the synthesis of oligosaccharide-branched cyclodextrins, which have potential binding to the saccharide-binding protein, lectin, were initially investigated. ${ }^{4}$ This kind of oligosaccharide-branched cyclodextrin can be adopted as a carrier of drugs in the hydrophobic cavity, and the oligosaccharides can recognize the targeting cell by sugar chain recognition through saccharide-protein complex.

In this study, the molecular interactions between immobilized Con A and newly synthesized oligosaccharidebranched CDs were studied using an optical biosensor equipped with a resonant mirror detector through the change in reflected laser light based on surface plasmon resonance (SPR) ${ }^{5}$ which corresponds to the mass on the surface of the metal. The advantages of this method are the conventional techniques includes high sensitivity, real time monitoring, and no requirement for the use of labeled materials. The number of publications in molecular interaction analysis using optical biosensor technology has rapidly increased. ${ }^{6-10}$

\section{EXPERIMENTAL}

\section{Materials}

Lactones of maltose, lactose, and glucose were prepared with $\mathrm{I}_{2}$ in methanol at $45^{\circ} \mathrm{C}$, followed by the dropwise addition of $4 \%$ potassium hydroxide-methanol solution and then desalted with an ion exchanger

\footnotetext{
${ }^{\dagger}$ To whom all correspondence should be addressed.
}

(Amberlite IR-120B) according to the literature. ${ }^{11} \mathrm{Mal}-$ tonolactone was produced with a yield of $75 \%$, TLC; $R f=0.16\left(\mathrm{BuOH}: \mathrm{EtOH}: \mathrm{H}_{2} \mathrm{O}=5: 4: 3\right.$, colored with anisaldehyde). Similarly, lactonolactone had a $59 \%$ yield, TLC; $R f=0.17$. D-Glucono-1,5-lactone was purchased from Tokyo Chemicals Industry. These lactones were connected with 6-monoamino- $\beta$-CD in DMF at $90^{\circ} \mathrm{C}$ for 3 days in the same manner as previously reported. ${ }^{4}$ The crude products were purified through an ion exchange column and preparative HPLC. The obtained $\alpha$-glucosylglucono-amide- $\beta$-CD (10), $\beta$-galactosyl-glucono-amide$\beta$-CD (11), and glucono-amide- $\beta$-CD (12) were identified from NMR and MS spectra. Characterization of compound 10: $100.4 \mathrm{MHz}{ }^{13} \mathrm{C}$ NMR $\left(\mathrm{D}_{2} \mathrm{O}\right) \delta 163(\mathrm{C}=$ O), 36 (C-N); MS (FAB): $m / z 1472.7\left(\mathrm{M}-\mathrm{H}^{-}\right)$; TLC Rf 0.25 ( $n$ - BuOH : EtOH: $\mathrm{H}_{2} \mathrm{O}=5: 4: 3$ ); Yield $4.3 \%$, of 11: $100.4 \mathrm{MHz}^{13} \mathrm{C}$ NMR $\left(\mathrm{D}_{2} \mathrm{O}\right) \delta 173(\mathrm{C}=\mathrm{O}), 38(\mathrm{C}-\mathrm{N})$; MS (FAB): $m / z 1473.5\left(\mathrm{M}-\mathrm{H}^{-}\right)$; TLC $R f$ 0.24; Yield $12.3 \%$, and of 12: $100.4 \mathrm{MHz}{ }^{13} \mathrm{C}$ NMR $\left(\mathrm{D}_{2} \mathrm{O}\right) \delta 173$;
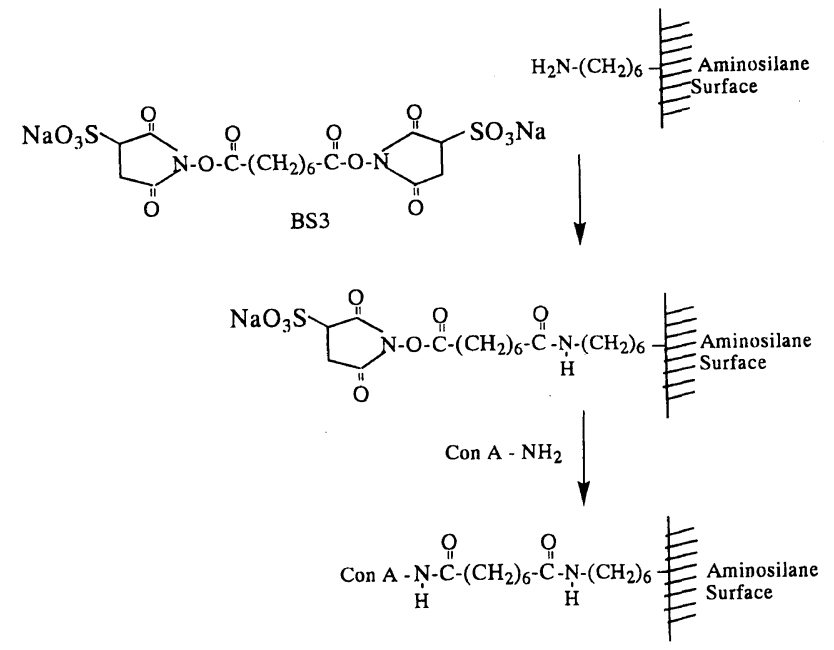

Scheme 1. The immobilization process of Con A on aminosilane surface. 


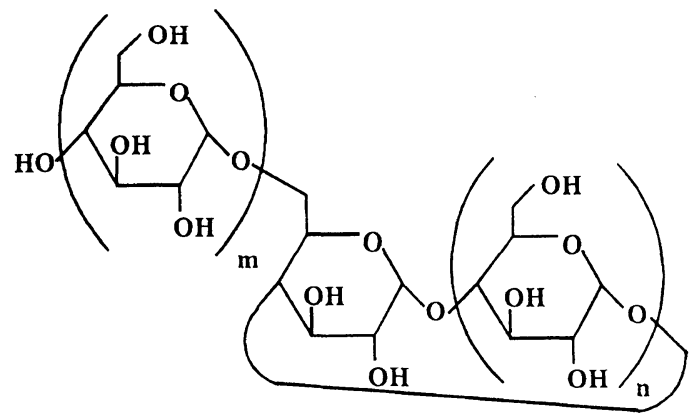

Scheme 2. The structure of CDs and oligosaccharide-branched CDs (1-9).

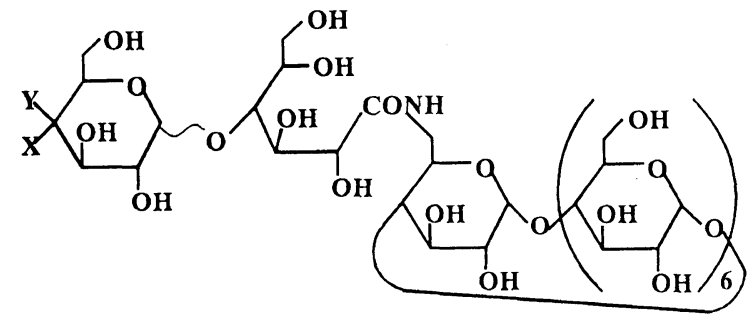

Scheme 3. The structure of oligosaccharide glucono-amide- $\beta-\mathrm{CD}$ (10, 11) and glucono-amide- $\beta$-CD (12).

MS (FAB): $m / z 1310.5\left(\mathrm{M}-\mathrm{H}^{-}\right)$, TLC $R f 0.20 ;$ Yield $7.6 \%$.

Glucosyl- $\alpha, \beta, \gamma-\mathrm{CD}$, maltosyl- $\alpha, \beta, \gamma-\mathrm{CD}$, and $\alpha, \beta, \gamma-\mathrm{CD}$ were available from Ensuiko Sugar Refining. Con A was purchased from Wako Chemicals. A cuvette of 200 $\mu$ l volume coated with aminosilane was supplied by FISONS Applied Sensor Technology. Bissulfosuccinimidyl suberate (BS3) was purchased from Pierce \& Warriner. Acetate buffer ( $\mathrm{pH} 5.3,10 \mathrm{mM}$ ) was made by titrating aqueous sodium acetate with $2 \mathrm{M}$ acetic acid.

\section{Immobilization of Con $A$ on the Optical Biosensor}

The process for the immobilization was illustrated in the Scheme 1. The typical immobilization conditions of Con A on a IAsys cuvette were described as follows; the aminosilane biosensor surfaces were activated with $200 \mu \mathrm{l}$ of $10 \mathrm{mM}$ phosphate buffered saline (pH 6.5) (PBS) for $8 \mathrm{~min}$. The BS3 $(1 \mathrm{mM})$ of the crosslinker solution was injected into the aminosilane cuvette and stirred for $10 \mathrm{~min}$. It was washed with PBS for $8 \mathrm{~min}$. This crosslinker attachment was repeated 3 times. After it was washed with PBS ( $8 \mathrm{~min})$ and acetate buffer $(\mathrm{pH}$ $5.3,10 \mathrm{mM})(2 \mathrm{~min})$, Con $\mathrm{A}\left(2 \mathrm{mg} \mathrm{ml}^{-1}\right.$ in the acetate buffer) was immobilized for $45 \mathrm{~min}$ by a reaction with the amino group. Moreover, its cuvette was washed with acetate buffer $(2 \mathrm{~min})$, blocked with $1 \mathrm{M}$ ethanolamine $(5 \mathrm{~min})$. The cuvette surface was washed with $\mathrm{NaOH}(\mathrm{pH}$ $8.90)$ for $5 \mathrm{~min}$ and acetate buffer $(2 \mathrm{~min})$. The change in the response position at the immobilization using the biosensor is shown in Figure 1. The response means interacting amounts of the substance to the adhesive surface. The net change in the response position caused by the immobilization of Con A ranged from 700 to 2000 (arc seconds) depending on the quality of Con $\mathrm{A}$ and the reaction conditions. As the sensitivity of the sensor was calibrated in the relation between the amount of the immobilization and the response of the reflected light angle, this figure denotes the amount of immobilized
Con A as approximately $4.4-12.3 \mathrm{ng} \mathrm{mm}^{-2}$ on the cuvette surface on the foundation of 163 arc seconds per $1 \mathrm{ng} \mathrm{mm}^{-2}$ measured directly by Edwards et al. using radio labeled HSA binding. ${ }^{6,7}$

\section{Interaction Analysis}

The operating conditions of the optical biosensor IAsys cuvette system (FISONS Applied Sensor Technology) with a resonant mirror detector (RMD) ${ }^{12,13}$ were as follows. Samples concentration of the CDs were prepared among $17 \mu \mathrm{M}-20 \mathrm{mM}$ so that the response position indicated clear changes. The assay time was usually less than $15 \mathrm{~min}$. The stirrer speed was $100 \mathrm{rpm}$. The temperature in the cuvette was controlled at $25.0 \pm 0.1^{\circ} \mathrm{C}$ by Pertier device. After the immobilization was completed, a $200 \mu \mathrm{l} \mathrm{CD}$ solution was injected into the cuvette and the change of response position was detected in real time and stored in the personal computer. The kinetic analysis was executed using the FASTfit software.

Determination of the Association Constant, $K_{\mathrm{a}}\left(=k_{\mathrm{a}} / k_{\mathrm{d}}\right)$

A linear fit was carried out as follows. Using the IAsys, the association rate constant $\left(k_{\mathrm{a}}\right)$ and the dissociation rate constant $\left(k_{\mathrm{d}}\right)$ can be calculated from the intercept of a plot of $\mathrm{d} R / \mathrm{d} t v s . R$ through the response in reflected light, $R$ (arc seconds), at the concentration of the branched $\mathrm{CD}$ as $\mathrm{C}$. If the maximum associating response, $R_{\max }$, was known and the interactions were carried out under pseudo first order conditions $\left(k_{\mathrm{a}} \gg k_{\mathrm{d}}\right)$ for which the relation is:

$$
\mathrm{d} R / \mathrm{d} t=k_{\mathrm{a}} R_{\max } C-\left(k_{\mathrm{a}} C+k_{\mathrm{d}}\right) R
$$

When $k_{\mathrm{a}} \gg k_{\mathrm{d}}$ is satisfied, the value $k_{\mathrm{a}}$ and $k_{\mathrm{d}}$ can be obtained by plotting $(\mathrm{d} R / \mathrm{d} t) \cdot R^{-1}$ (= on rate constant, $k_{\text {on }}$ ) with changing $C$.

The examples of the plotting are illustrated in Figures 3 and 5.

Scatchard plotting was carried out according to the following relation,

$$
v /[\mathrm{CD}]_{\mathrm{free}}=K_{\mathrm{a}}(1-v)
$$

where $v=[$ Con $\mathrm{A} \cdot \mathrm{CD}] /\left\{[\mathrm{Con} \mathrm{A} \cdot \mathrm{CD}]+[\mathrm{Con} \mathrm{A}]_{\text {free }}\right\}$. In this relation, $v$ is proportional to the observed change of the response by the association, $\Delta R$, and also $[\mathrm{CD}]_{\mathrm{free}}$ is nearly equal to the added [CD]. Then, plotting $\Delta R /$ [CD] vs. $\Delta R$, the slope gave the association constant, $K_{\mathrm{a}}$, as illustrated in Figure 6.

\section{RESULTS AND DISCUSSION}

\section{Immobilization of Con A on the Optical Biosensor}

The conditions of the immobilization for Con A were investigated concerning the $\mathrm{pH}$, the presence of metal ions, regeneration conditions, and the reproducibility. The typical immobilization conditions of Con A on an sensor cuvette were described in the EXPERIMENTAL section and Figure 1. There is a reversible dimer-tetramer equilibrium of Con A. ${ }^{14}$ In this experiment, Con $\mathrm{A}$ was immobilized as a dimer using acetate buffer of $\mathrm{pH} 5.3$ at $25^{\circ} \mathrm{C}$. The concentrations of $\mathrm{MnCl}_{2}$ and $\mathrm{CaCl}_{2}$ were maintained at $1 \mathrm{mM}$ in the buffer solution. The regeneration condition was carried out by washing $\mathrm{NaOH}$ of $\mathrm{pH} 8.9$ or $20 \%$ aqueous methanol solution. An 
experimental run was always repeated more than three times until the reproducibility was satisfied. The standard error for the kinetic results was indicated.

Sugar Chain Recognition between Con A and Oligosaccharide-Branched CDs (10-12)

The biosensor was applicable for investigating for the interaction analysis, such as the association constant between the various oligosaccharide-branched CDs and Con A. Figure 2 presents a profile of the interaction curve of the newly synthesized oligosaccharide-branched CDs with Con A using the optical biosensor IAsys. From the results of Figure 2, only the $\alpha$-glucosyl-gluconoamide- $\beta$-CD (10) showed an interaction but not $\beta$ galactosyl-glucono-amide- $\beta$-CD (11), glucono-amide- $\beta$ CD (12), or $\beta$-CD (4). The linear fit between (10) and $k_{\text {on }}$ gave the plotted result as shown in Figure 3. The association rate constant, $k_{\mathrm{a}}$, of the glucosyl-glucono-amide$\beta$-CD (10) and dissociation rate constant, $k_{\mathrm{d}}$, were obtained as $(1.08 \pm 0.10) \times 10^{2} \mathrm{M}^{-1} \mathrm{~s}^{-1}$ and $(1.26 \pm 0.02) \times$ $10^{-2} \mathrm{~s}^{-1}$, respectively. Therefore, the association constant, $K_{\mathrm{a}}$, was calculated to be $8570 \pm 880 \mathrm{M}^{-1}$. The results of the association constants are summarized in Table I. The reported $K_{\mathrm{a}}$ values ${ }^{15,16}$ between Con A and the oligomannoses were approximately the same as the present results in the range of $10^{3}-10^{5} \mathrm{M}^{-1}$. However, oligosaccharides of the trianntena type having mannosyl units to Con $\mathrm{A}^{16}$ showed more than $10^{7} \mathrm{M}^{-1}$ for the $K_{\mathrm{a}}$ values. The present results can be summarized such that

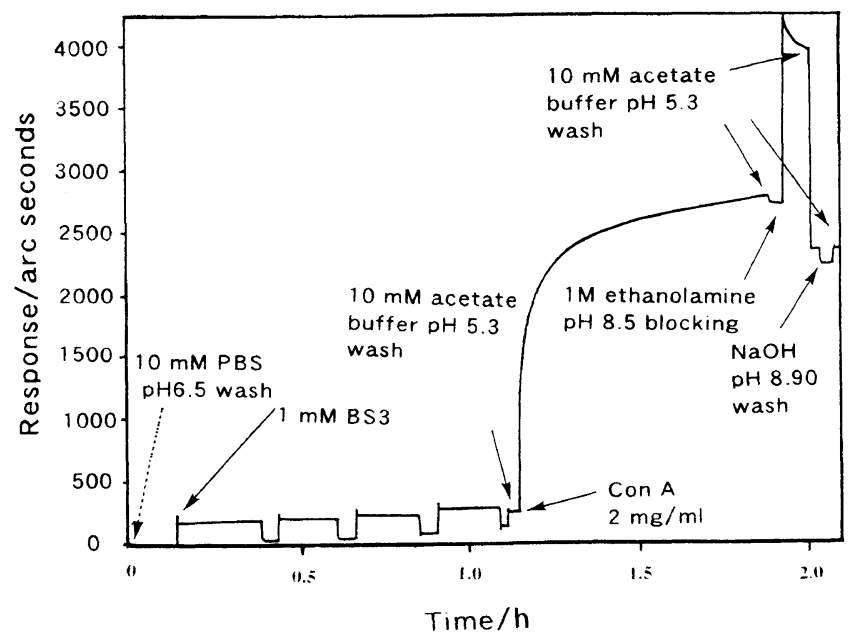

Figure 1. A profile for immobilization of Con $\mathrm{A}$ on the aminosilane surface by optical biosensor. only the CD derivative (10) having a glucose unit at the non-reducing end, interacted with Con A strongly.

The recognition of Con $\mathrm{A}$ for the oligosaccharide showed a very sharp dependency on the type of saccharides. Con A was associated with glucosyl derivative (10) but not with galactosyl derivative (11). The length and flexibility of the spacer between the glucosyl unit and $\mathrm{CD}$ cavity also seems to be important conditions for

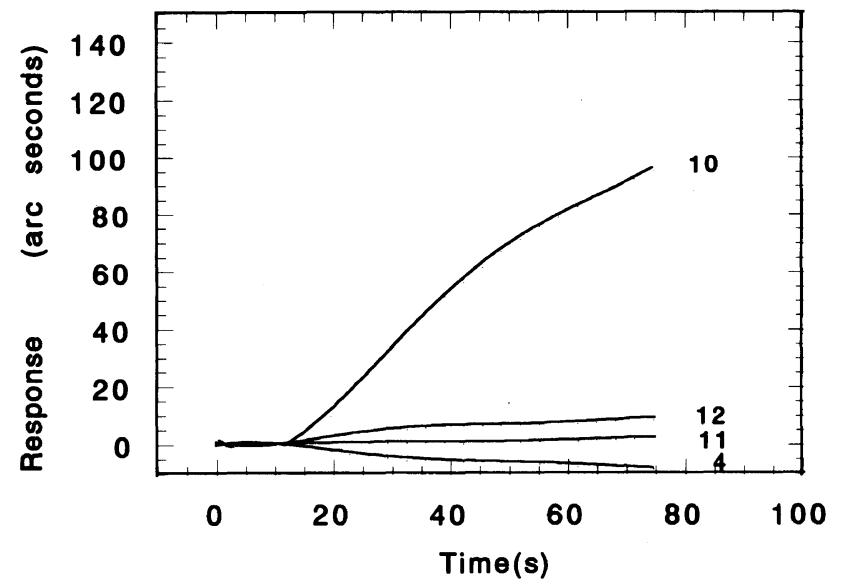

Figure 2. Interaction between Con $A$ and oligosaccharide-branched CDs; $\beta$-CD (4), glucosyl-glucono-amide- $\beta$-CD (10), and galactosylglucono-amide- $\beta$-CD (11), glucono-amide- $\beta$-CD (12), at $25.0 \pm 0.1^{\circ} \mathrm{C}$, pH 5.3 in acetate buffer containing $1 \mathrm{mM} \mathrm{MnCl}, 1 \mathrm{mM} \mathrm{CaCl}, 100 \mathrm{mM}$ $\mathrm{NaCl},[\mathrm{CDs}]=17 \mu \mathrm{M}$.

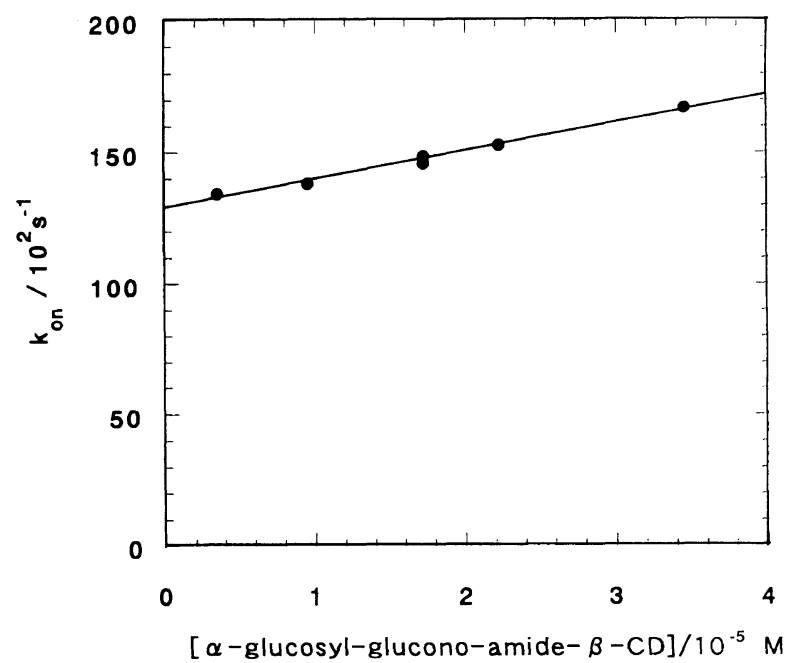

Figure 3. Plots of the linear fit for the interaction analysis between Con $\mathrm{A}$ and $\alpha$-glucosyl-glucono-amide- $\beta$-CD (10).

Table I. Association constants for the oligosaccharide-branched $\mathrm{CDs}^{\mathrm{a}}$

\begin{tabular}{|c|c|c|}
\hline Structure & Compound & $K_{\mathrm{a}}\left(\mathrm{M}^{-1}\right)$ \\
\hline \multicolumn{3}{|l|}{ Scheme 2} \\
\hline$n=6, m=0$ & $\beta-\mathrm{CD} \quad(\mathbf{4})$ & $<1$ \\
\hline 1 & Glucosyl- $\beta$-CD (5) & $<1$ \\
\hline 2 & Maltosyl- $\beta$-CD (6) & $134 \pm 18$ \\
\hline$n=7, m=0$ & $\gamma-C D$ & $<1$ \\
\hline 1 & Glucosyl- $\gamma-\mathrm{CD} \quad$ (8) & $<1$ \\
\hline 2 & Maltosyl- $\gamma-\mathrm{CD}$ & $833 \pm 11$ \\
\hline \multicolumn{3}{|l|}{ Scheme 3} \\
\hline $\mathrm{X}=-\mathrm{OH}, \mathrm{Y}=-\mathrm{H}$ & $\alpha$-Glucosyl-glucono-amide- $\beta$-CD $\quad(\mathbf{1 0})$ & $8570 \pm 880$ \\
\hline $\mathrm{X}=-\mathrm{H}, \mathrm{Y}=-\mathrm{OH}$ & $\beta$-Galactosyl-glucono-amide- $\beta$-CD & $<1$ \\
\hline & Glucono-amide- $\beta$-CD (12) & $<1$ \\
\hline
\end{tabular}

${ }^{a}$ In $10 \mathrm{mM}$ acetate buffer of $\mathrm{pH} 5.3$ at $25.0 \pm 0.1^{\circ} \mathrm{C}$; [CDs $\left.(\mathbf{1}-\mathbf{9})\right]=20 \mathrm{mM}$ and $[\mathrm{CDs}(\mathbf{1 0 - 1 2})]=17 \mu \mathrm{M}$. 
Table II. Interaction between immobilized concanavalin A and the oligosaccharide-branched CDs using optical biosensor ${ }^{\mathbf{a}}$

\begin{tabular}{|c|c|c|}
\hline Structure & Compound & $\mathrm{pH} 5.3$ \\
\hline \multicolumn{3}{|l|}{ Scheme 2} \\
\hline$n=5, m=0$ & $\alpha-\mathrm{CD}$ & 0 \\
\hline 1 & Glucosyl- $\alpha-\mathrm{CD}$ & 0 \\
\hline 2 & Maltosyl- $\alpha-\mathrm{CD}$ & 0 \\
\hline$n=6, m=0$ & $\beta-\mathrm{CD}$ & 0 \\
\hline 1 & Glucosyl- $\beta$-CD (5) & - \\
\hline 2 & Maltosyl- $\beta$-CD (6) & + \\
\hline$n=7, m=0$ & $\gamma-\mathrm{CD}$ & 0 \\
\hline 1 & Glucosyl- $\gamma-\mathrm{CD}$ & 0 \\
\hline 2 & Maltosyl- $\gamma$-CD (9) & + \\
\hline \multicolumn{3}{|l|}{ Scheme 3} \\
\hline $\mathrm{X}=-\mathrm{OH}, \mathrm{Y}=-\mathrm{H}$ & $\alpha$-Glucosyl-glucono-amide- $\beta$-CD & ++++ \\
\hline $\mathrm{X}=-\mathrm{H}, \mathrm{Y}=-\mathrm{OH}$ & $\beta$-Galactosyl-glucono-amide- $\beta$-CD & 0 \\
\hline & Glucono-amide- $\beta$-CD (12) & 0 \\
\hline
\end{tabular}

${ }^{a}$ Acetate buffer of $\mathrm{pH} 5.3$ was used at $10 \mathrm{mM}$ containing $1 \mathrm{mM} \mathrm{CaCl}{ }_{2}, 1 \mathrm{mM} \mathrm{MnCl}_{2}$, and $100 \mathrm{mM} \mathrm{NaCl}$ at $25.0 \pm 0.1^{\circ} \mathrm{C}$ with $[1-9]=$ $20 \mathrm{mM}$ and $[10-12]=17 \mu \mathrm{M}$. Sign $(+),(-)$, and 0 show the increase, decrease or no change of the response by using the optical biosensor, respectively.

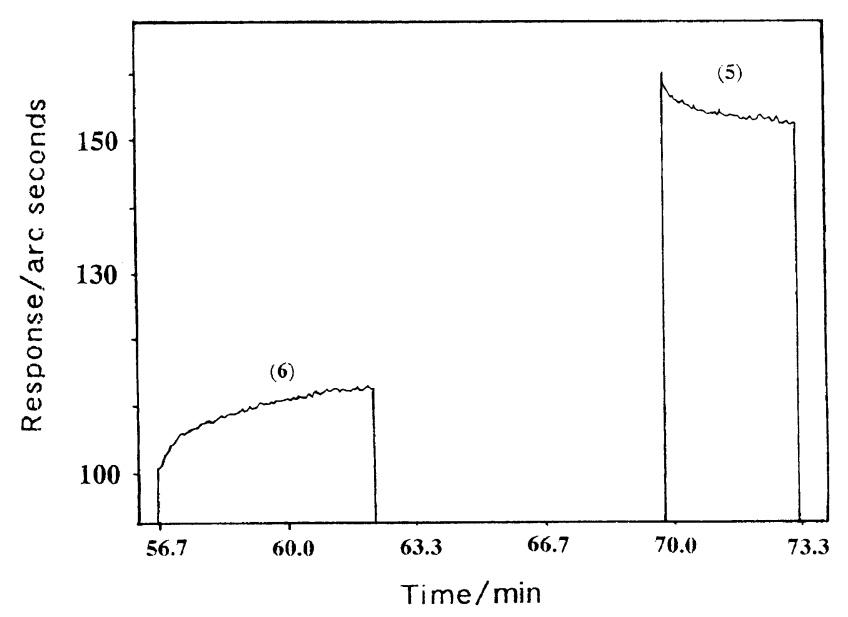

Figure 4. Profiles of Con $\mathrm{A}$ interacting to glucosyl- $\beta-\mathrm{CD}$ (5) and maltosyl- $\beta$-CD (6) by optical biosensor at $25.0 \pm 0.1^{\circ} \mathrm{C}, \mathrm{pH} 5.3$, in acetate buffer, [glucosyl- $\beta-\mathrm{CD}]=[$ maltosyl- $\beta-\mathrm{CD}]=20.0 \mathrm{mM}$.

the interaction with Con A. The non-reducing end of the newly synthesized oligosaccharide-branched CD (10) would behave more flexible movement than that of the commercially available $6-O$-glucosyl and maltosyl $\beta$-CDs $(\mathbf{5}, \mathbf{6})$.

\section{Weak or Obscure Interaction between Con A and Oligo- saccharide CDs (1-9)}

The behavior of the interaction of all the commercially available oligosaccharide-branched $\mathrm{CD}$ derivatives with immobilized dimeric Con $\mathrm{A}$ was also examined at $\mathrm{pH}$ 5.3 using the biosensor. The summarized results are shown in Table II.

Typical profiles of Con A interacting with glucosyl- $\beta$ $\mathrm{CD}(5)$ and maltosyl- $\beta$-CD (6) using an optical biosensor at $25.0 \pm 0.1^{\circ} \mathrm{C}, \mathrm{pH} 5.3$, in acetate buffer are shown in Figure 4 . The concentration of CDs was adjusted to $20.0 \mathrm{mM}$. In the case of 6 , the response curve showed an association. On the contrary, in the case of 5, a decreased response curve was observed.

The linear fit of Con A and maltosyl- $\gamma-\mathrm{CD}(9)$ provided the kinetic results as in Figure 5 and Scatchard plots of Con $\mathrm{A}$ and maltosyl- $\beta$-CD (6) gave the association constants results as in Figure 6. The association con-

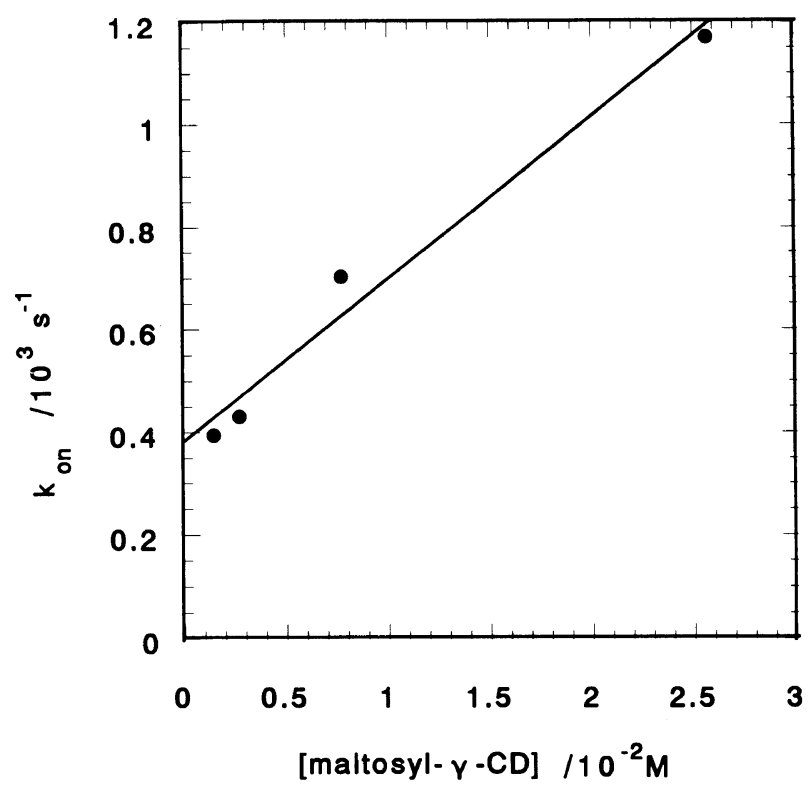

Figure 5. Linear fit of Con $A$ and maltosyl- $\gamma-C D(9)$, at $25.0 \pm 0.1^{\circ} \mathrm{C}$, $\mathrm{pH} 5.3$, in acetate buffer, [maltosyl- $\gamma-\mathrm{CD}]=0-30.0 \mathrm{mM}$.

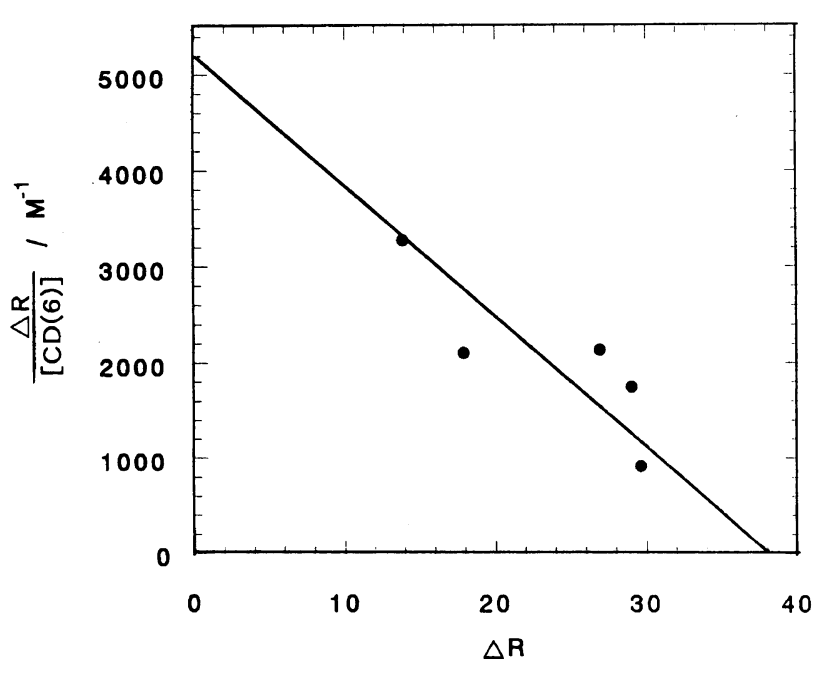

Figure 6. Scatchard plots between Con $\mathrm{A}$ and maltosyl- $\beta-\mathrm{CD}(6)$, at $25.0 \pm 0.1^{\circ} \mathrm{C}, \mathrm{pH} 5.3$, in acetate buffer, [maltosyl $\left.\gamma-\mathrm{CD}\right]=0-30.0 \mathrm{mM}$. $\Delta R$ is the observed change of the response by the optical biosensor. 
stants, $K_{\mathrm{a}}$, of maltosyl- $\beta$-CD (6) and maltosyl- $\gamma$-CD (9) were calculated to be 134 and $833 \mathrm{M}^{-1}$, respectively.

The other compounds, $1-\mathbf{4 , 7 , 8}$ did not interact with Con A. These oligosaccharide-branched CDs (1-9) showed rather complicated and obscure interaction.

\section{CONCLUSION}

This investigation has demonstrated the convenient applications of an optical biosensor IAsys equipped with a resonant mirror detector to determine the kinetics for the interaction of the oligosaccharide-branched CDs with immobilized Con A on the surface of the aminosilane cuvette.

The behavior of the interaction of various oligosaccharide CD derivatives with immobilized Con $\mathrm{A}$ is summarized as follows: $\beta$ - and $\gamma$-CD derivatives that have a glucosyl unit at the non-reducing end of the sugar chain, which is longer than the maltosyl group, showed association with immobilized Con A using the optical biosensor. When the spacer between CD and the glucose unit is suitable, the association constant for the oligosaccharide-branched CD increases. We now can assume that the behavior of the interaction is as follows: there should be a stereospecific molecular recognition between the correctly fitting oligosaccharide-branched CD and the Con A.

By using this method, it will be possible to obtain the precise kinetic results for the interaction between the Con $\mathrm{A}$ and various oligosaccharide-CD derivatives. And the development to the targeting drug delivery system, will be possible by the hydrophobic cavity of the oligosaccharide-CD derivatives.

\section{REFERENCES}

1. J. Szejtli, "Cyclodextrin Technology," Kluwer Academic Publishers, Dordorecht, 1988.

2. K. H. Froming and J. Szejtli, "Cyclodextrin in Pharmacy," Kluwer Academic Publishers, Dordorecht, 1993.

3. I. J. Goldstein and R. D. Poretz, "The Lectin," Academic Press, Orlando, 1986, p 51.

4. K. Hattori, K. Takahashi, and T. Koshikawa, "Proceedings of 7th International Cyclodextrins Symposium," T. Osa, Ed., Business Center for Academic Societies Japan, Tokyo, 1994, pp $90-93$.

5. S. C. Schuster, R. V. Swanson, L. A. Alex, R. B. Bourret, and M. I. Simon, Nature, 365, 343 (1993).

6. P. R. Edwards, A. Gill, D. V. Pollard-Knight, M. Hoare, P. E. Buckle, P. A. Lowe, and R. J. Leatherbarrow, Anal. Biochem., 231, 210 (1995).

7. R. J. Davies, P. R. Edwards, H. J. Watts, C. R. Lowe, P. E. Buckle, D. Yeung, T. M. Kinning, and D. V. Pollard-Knight, "Techniques in Protein Chemistry V," Academic Press, San Diego, 1994, pp 285-292.

8. R. Cush, J. M. Cronin, W. J. Stewart, C. H. Maule, J. Molloy, and N. J. Goddard, Biosensors Bioelectronics, 8, 347 (1993).

9. H. Sumitomo, K. Hata, K. Mizuki, T. Ito, Y. Sasaki, Y. Fukumaki, M. Nakamura, and K. Takeshige, J. Biol. Chem., 271, 22152 (1996).

10. K. Yamamoto, C. Ishida, Y. Shinohara, Y. Hasegawa, Y. Konami, and T. Osawa, Biochemistry, 33, 8159 (1994).

11. K. Kobayashi, H. Sumitomo, and Y. Ina, Polym. J., 17, 567 (1985).

12. Z. Salamon, Y. Wang, M. F. Brown, H. A. Macleod, and G. Tollin, Biochemistry, 33, 13706 (1994).

13. H. A. Macleod, "Tutorials in Optics," D. T. Moore, Ed., Optical Society, Washington, D.C., 1992, p 121.

14. M. Huet, Eur. J. Biochem., 59, 627 (1975).

15. A. Van Landschoot, F. G. Loontiens, and C. K. De Bruyne, Eur. J. Biochem., 103, 307 (1980).

16. T. Mega, H. Oku, and S. Hase, J. Biochem., 111, 396 (1992). 